\title{
El drama en verso moderno: Asesinato en la catedral (1935) de T.S. Eliot
}

\section{María Angelina Cazorla}

Facultad de Humanidades de la Universidad Nacional del Nordeste (UNNE), Argentina

angelinacazorla@hotmail.com

Fecha de recepción: 25/03/2020. Fecha de aceptación: 19/04/2020

\begin{abstract}
Resumen
T.S. Eliot (1888-1965) presentó Asesinato en la catedral en el Festival Anual de Canterbury en 1935. Canterbury era no sólo la arquidiócesis del Estado de Kent, sino el santuario cristiano más antiguo de Europa, cuyo culto fue la razón del viaje de los peregrinos de Geoffrey Chaucer. Eliot escogió a Thomas Becket, héroe nacional y religioso inglés, como objeto de su drama en verso. Sin embargo, el dramaturgo decidió no poner, nuevamente, el foco de la acción en el conflicto histórico-político entre Enrique II Plantagenet y su ex canciller, pues la lucha de investiduras del siglo XII que finalizó con un brutal asesinato de Becket en la catedral durante el día de Navidad de 1170, era el tema obligado en estos festivales anglo-católicos. En esta ocasión, la mirada se posó en el conflicto moral del arzobispo: sus íntimas reflexiones sobre la naturaleza real del martirio. Quien es quizás, el más grande de los poetas modernos, nos ofrece una obra de teatro comercial para una audiencia moderna que, paradójicamente, contiene líneas corales al modo del drama griego, tradición litúrgica y abstracciones al estilo de las moralidades inglesas. Esta obra teatral, con aire de grandeza antigua y escenas de ritmo lento y parsimonioso, se escribió en la época del crecimiento del fascismo en Europa central, y puede entenderse como una protesta para que los individuos de los países afectados se opusieran a la tergiversación de los ideales de la Iglesia cristiana por parte del régimen nazi.
\end{abstract}

Palabras clave: Eliot, drama en verso, asesinato, martirio, Asesinato en la catedral

\section{Modern drama in verse: Murder in the Cathedral (1935) by T.S. Eliot}

\author{
Abstract \\ T.S. Eliot (1888-1965) presented Murder in the Cathedral at the Annual Canterbury \\ Festival in 1935. Canterbury was not only the archdiocese of Kent State, but also the \\ oldest Christian shrine in Europe whose cult was the reason for the pilgrims' journey \\ in Geoffrey Chaucer's tales. Eliot chose Thomas Becket, the national and religious \\ hero, as the object of his drama in verse. However, the playwright decided not to put,
}


again, the focus of action in the well-known historical-political conflict between Henry II Plantagenet and his former chancellor. The twelfth century struggle of investiture which ended with the brutal murder of Becket in the Cathedral during the Christmas Day of 1170 was the exclusively the subject in these Anglo-Catholic festivals. On this occasion, the viewpoint was on the archbishop's moral conflict: his intimate reflections on the real nature of martyrdom. Eliot, who is, perhaps, the greatest of modern poets, offers us a commercial play for a modern audience, which, paradoxically, contains choral lines in the manner of Greek drama, liturgical tradition and abstractions in the style of English moralities. This play, with an air of old grandeur and scenes of slow and parsimonious rhythm, was written at the time of the beginning of fascism in central Europe, and can be understood as a protest aimed to encourage citizens from affected countries to oppose the misrepresentation of the ideals of the Christian Church on the part of the Nazi regime.

Keywords: Eliot, Drama in Verse, Murder, Martyrdom, Murder in the Cathedral

\section{Introducción}

T.S. Eliot (1888-1965) presentó Asesinato en la catedral el 13 de junio de 1935 en el Chapter House de la Catedral de Canterbury. La ocasión era la celebración del Festival Anual organizado con el objeto de recaudar fondos para la construcción de una nueva iglesia. Es así que el texto no debe su existencia a una inspiración poética, sino a un encargo eclesiástico.

Canterbury era no sólo la arquidiócesis del Estado de Kent, sino el santuario cristiano más antiguo de Europa, cuyo culto fue la razón del viaje de los peregrinos de la obra del autor bajo-medieval Geoffrey Chaucer. En ella, Santo Thomas Becket fue inmortalizado en la literatura por primera vez en el Prólogo General de The Canterbury Tales, obra escrita entre los años 1387 y 1400. En las primeras dieciocho líneas, Chaucer menciona que, al comienzo de la primavera (abril), la gente peregrina al santuario de Canterbury para honrar los restos sagrados del mártir que los alivió en la enfermedad y el sufrimiento espiritual. Siglos después, Eliot escogió a Thomas Becket, héroe nacional y religioso, como objeto de su drama en verso moderno. Sin embargo, el dramaturgo decidió no poner, como en festivales anteriores, el foco de la acción en el conflicto histórico-político entre el rey Enrique II Plantagenet y su ex canciller. No obstante, la cuestión se explica retrospectivamente al comienzo de la obra, donde refiere esta lucha de supremacías del siglo XII que finalizó con el brutal asesinato de Becket al pie del altar de la iglesia donde era sumo sacerdote. El 29 de diciembre de 1170, día en que desde entonces se celebra la festividad de Santo Tomás Becket, y por orden del rey, fue atravesado por las espadas de cuatro caballeros leales al poder monárquico. Eliot no se desvió de la tradición ni de los hechos históricos, sino que, en esta oportunidad, Dios entra en la historia y la mirada se posa en el conflicto moral del arzobispo y sus íntimas reflexiones sobre la naturaleza real del martirio, unos pocos días antes de su muerte. Así, el tema de la obra no es el crimen, como sugiere el título, sino una exploración del estado espiritual de un mártir en el umbral de su inmolación. En 1927, Eliot había sido bautizado y confirmado en la iglesia anglicana y, desde ese momento, todos sus trabajos se tiñeron de un profundo color cristiano. Fue sólo cuestión de tiempo que sus intereses dramáticos se pusieran al servicio del culto a la latría (Tydeman, 2008).

\section{El drama en verso}

La afición de Eliot por el teatro poético era ampliamente conocida. Para aquella época ya había escrito The Wasted Land (1922), Ash Wednesday (1930) y The Rock (1933). Eliot 
justifica la elección del drama en verso argumentando que le permite una experiencia más profunda y compleja que la simplicidad superficial de la prosa. El ritmo, el metro, la forma versal (rima ocasional y aliteración) y las imágenes, entre otros recursos literarios, orquestan la obra como si fuera una pieza musical (Poetry and Drama, 2015). Obviamente, este texto no podría haber sido escrito como la poesía del anglo-sajón o el francés normando del siglo XII, ya que la lengua debía ser lo suficientemente vívida como para atraer a la audiencia moderna y, aun así, convencerla de viajar a un tiempo históricamente remoto.

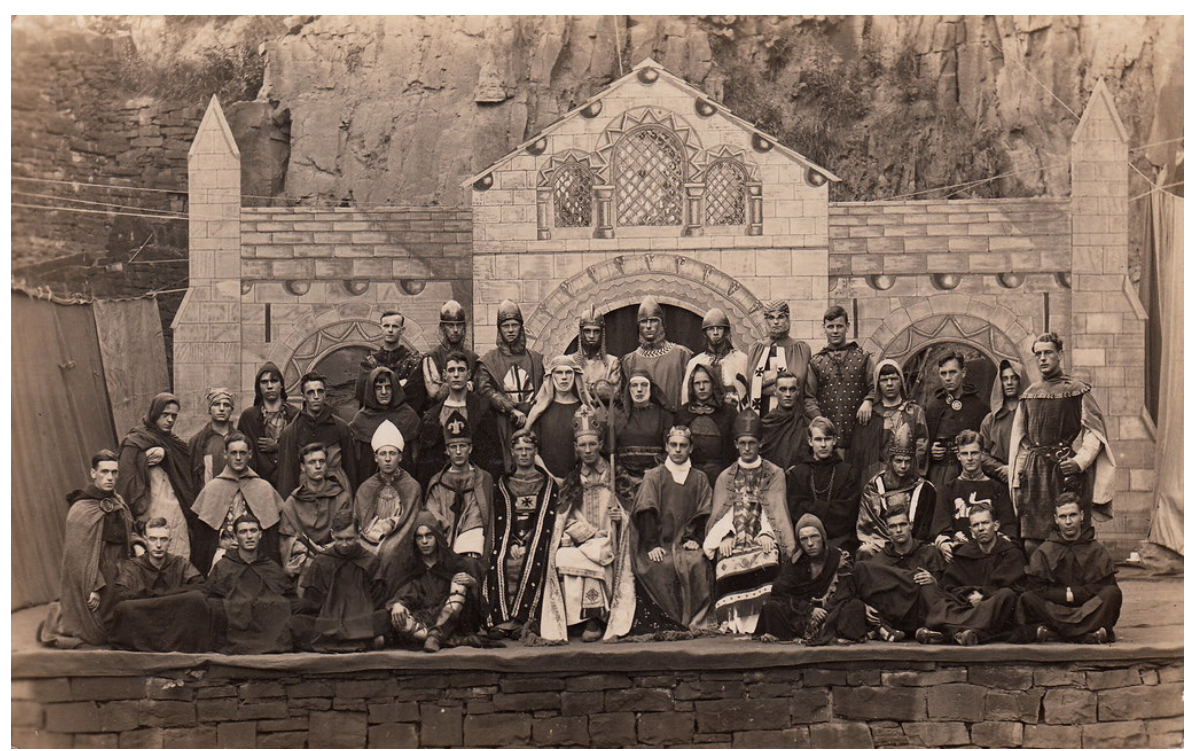

Elenco de Murder in the Cathedral para la representación teatral de Quarry Theatre, House of the Resurrection, Mirfield, West Yorkshire (Londres, 1935). Fuente: https://www.flickr.com/photos/pellethepoet/9798396723/in/photostream/

La obra,dividida en dos partes, cuatro escenas y un sermón a modo de interludio, describe los últimos días de la vida de Thomas Becket, después de regresar a Inglaterra tras siete años de exilio en Francia. Su pasado libertino, su amistad con el rey, sus funciones como canciller y el conflicto ente Iglesia y Estado (posteriormente se profundizará con Enrique VIII y el Papa Clemente VII) son resumidos en líneas corales al modo de un agón griego. Sin lugar a dudas, la inserción de un Coro, conformado por un número indefinido de mujeres pobres y simples de Canterbury, resuelve, con ritmo litúrgico, los problemas de exposición narrativa, pues Eliot asumía que la gran mayoría de los espectadores conocía la historia en sus líneas básicas. Las seis largas intervenciones corales producen un duelo verbal con Becket, fundamentando (en términos poco cristianos y nada teológicos) en tres ejes principales: la constitución espiritual de un mártir próximo a la muerte, la gradual conversión de las mujeres de Canterbury (desde una especie de letargo espiritual hasta llegar a un absoluto fervor místico) y la inaplazable separación del poder de la Iglesia y el del Estado. Los comentarios y las interpretaciones de este personaje colectivo nos permiten rastrear el camino del arrepentimiento de Becket como consecuencia de su arrogancia, su soberbia, su orgullo excesivo y su anterior vinculación con el poder político.

En la Parte I, Thomas Becket descubre la impureza de los motivos que lo conducirán al martirio: el ansia de inmortalidad. En ese sentido, los Cuatro Tentadores (personajes alegóricos) con provocativas intervenciones (que van aumentando en complejidad y perversión) conocen las ambiciones y pretensiones de Becket y, por ello, juegan un rol secundario, pero fundamental. Sin lugar a dudas, la cuarta y última tentación es la más 
insidiosa por ser inesperada (recuérdese que, según los evangelios de Mateo (4:1-11) y Lucas (4:1-13), Jesús sólo habría sufrido tres tentaciones en el desierto). El Cuarto Tentador le asegura la grandeza eterna a través del martirio y la auto-gratificación de saberse con un poder espiritual invulnerable a los efectos del tiempo:

But think, Thomas, think of glory after death.

When King is dead, there's another King

And one more King is another reign.

King is forgotten, when another shall come:

Saint and Martyr rule from tomb.

Think, Thomas, think of enemies dismayed,

Creeping in penance frightened of shade;

Think of pilgrims, standing in line

Before the glittering jewelled shine, For generations to generations

Bending the knee in supplication,

Think of miracles, by God's grace,

And think of your enemies, in another place. (Eliot, 2016: 49-50)

Rechazada esta tentación final, el camino para Becket es claro y luminoso. En un breve sermón tomado del evangelio de San Lucas 2: 1-14 (exposición directa y prosaica), pronunciado en la mañana de la Navidad de 1170, explora la tesis central de la obra: la naturaleza real del martirio:

A Christian martyrdom is never an accident, for Saints are not made by accident. Still less is a Christian martyrdom the effect of man's will to become a Saint, as a man by willing and contriving may become a ruler of men. A martyrdom is always the design of God, for His love of men, to warn them and to lead them, to bring them back to His ways. It is never the design of man; for the true martyr is he who has become the instrument of God, who has lost his will in the will of God, and who no longer desires anything for himself, not even the glory of becoming a martyr (2016: 49-50).

En este hiato que separa las dos partes del drama, hace referencia a la paz (espiritual y temporal) que significó el nacimiento de Cristo y prepara a su congregación para su destino, pues el verdadero mártir subordina su deseo al de Dios y pierde su propia voluntad. En este sentido, María Enriqueta González Padilla en Poesía y teatro de T.S. Eliot, comenta:

A semejanza de Cristo, Becket obtiene con su martirio una victoria moral que transforma en triunfo la catástrofe. El drama describe un recorrido en que la tristeza se torna en gozo; el horror en gloria, y al que contribuyen, además del propio Becket, por una parte los Tres Sacerdotes, y el Coro de mujeres de Cantórbery, y por otra, los Cuatro Tentadores y los Cuatro Caballeros (1991: 91).

Por otro lado, la Parte II, cuya primera escena se desarrolla en el Palacio Arzobispal, es más ágil y rica en contrastes. Al parlamento del Coro, le suceden las intervenciones de los Tres Sacerdotes, cantando los introitos de las misas de los primeros mártires del año litúrgico (San Esteban, San Juan Evangelista y los Santos Inocentes). La tensión sube de improviso cuando irrumpen los Cuatro Caballeros. Estos (cuyos nombres 
son los tristemente célebres de los históricos asesinos: Reginal Fitzurse, Sir Hugh De Morville, Baron William De Traci y Richard Brito) entran a la Catedral, lugar donde trascurre la segunda escena, agresivos y amenazantes. Rechazan la cordial hospitalidad de los sacerdotes, acusan a Becket de complotar contra el rey y le recuerdan que aún sigue siendo un súbdito de la corona. Luego de un duelo verbal que se traba implacable entre el arzobispo y los esbirros del rey, el asesinato es hermosamente ejecutado sobre el escenario. Un acto de extrema violencia en forma ritual y sin sensacionalismos, que desencadena el pánico de los sacerdotes y del Coro, testigos presenciales de la escena.

Acto seguido, los asesinos se adelantan al proscenio y se dirigen a la audiencia, exhortándola a escuchar los diferentes alegatos antes de juzgar el crimen. El cambio del ritmo de la poesía a la prosa coloquial marca la coyuntura entre lo espiritual y lo mundano. Esta apología, presentada inmediatamente después del hecho se asemeja más a una parodia de cuatro oradores sobre una tribuna política que a un intento serio de justificación de motivos. Los caballeros argumentan que provienen de la esfera del Estado Nacional, quien antecede a la fe y la religión y, por ello, justifican el asesinato por lealtad y fidelidad al monarca. Concluyen sus pseudo-intelectuales alegatos dejando en claro que la violencia es el único modo de hacer justicia y que el arzobispo eligió deliberadamente el martirio, cometiendo, en definitiva, suicidio. El cuarto caballero, Richard Brito, lo expone en los siguientes términos:

[...] Who killed the Arch-bishop? As you have been eye-witnesses of this lamentable scene, you may feel some surprise at my putting in this way. But consider the course of events. [...] I think, with these facts before you, you will unhesitatingly render a verdict of suicide while of Unsound Mind. It is the only charitable verdict you can give, upon one who was, after all, a great man (Eliot, 2016: 61-62).

El drama culmina con la interpretación del Primer Sacerdote: el martirio de Becket no es derrota, desolación y pérdida; sino renovación y fortalecimiento para la Iglesia. Predice, además, el castigo de los asesinos a quienes, según la historia, aguardan el remordimiento, el naufragio y el exilio. A lo lejos, suena un bellísimo Te Deum en latín que certifica la santidad del mártir y anticipa su beatificación, al mismo tiempo que el Coro se propone glorificar a Dios hasta en las obras más humildes de todas las criaturas:

[...]

Lord, have mercy upon us

Blessed Thomas, pray for us. (2016:73-74)

\section{A modo de conclusión}

El asunto y la ocasión para la que T. S. Eliot escribió Murderin the Catedral, permitieron al maduro talento de un poeta, cuyo verso era por esencia dramático, aprovechar los múltiples recursos de la liturgia del dogma cristiano y enlazar sabiamente presente y pasado. El teatro, que en la Edad Media naciera al amparo de la Iglesia, volvía ahora a la Iglesia. Quien es, quizás, el más grande de los poetas modernos, nos ofrece una obra de teatro por encargo para una audiencia moderna que, paradójicamente, contiene desde líneas corales al modo de los ancianos tebanos de Edipo Rey de Sófocles; antífonas del ritual cristiano; cánticos litúrgicos (Dies Irae II, 279-309, Te Deum II, 61850); textos bíblicos (el sermón de Becket), hasta abstracciones alegóricas y discursos de personajes menores (el mensajero, los sacerdotes y los caballeros del rey). Es, en 
definitiva, un texto versátil, capaz de expresar lo mundano y lo profundo, lo ordinario y lo elevado, las vanidades cotidianas y la intervención divina. Eliot omite toda referencia al nombre del prelado en el título; sin embargo, deja de manifiesto que se trata de un asesinato (y no una muerte) para reforzar el sentido de pasividad o entrega voluntaria al plan de Dios que define la postura del clérigo. Sólo el recinto sagrado (la sede catedralicia) adquiere el privilegio de ser aludido, pues con su explicitación la muerte adquiere la categoría de sacrificio humano.

Eliot no se desvía de las crónicas que recuerdan la confrontación entre dos personalidades histórica y espiritualmente poderosas; pero lleva su narrativa a un plano superior de la existencia. El conflicto esencial es interno: entre Thomas Becket y él mismo, porque su gran orgullo lo hace ambicionar, incluso, el martirio. El mismo arzobispo se cuestiona si es lícito llevar a cabo dudosos proyectos con fines loables:

The last temptation is the greatest treason:

To do the right deed for the wrong reason,

The natural vigour in the venial sin

Is the way in which our lives begin. (2016:79)

Su aspiración espiritual se confronta con sus propios deseos. La ambición es una trampa que se refleja en cada una de las proposiciones de los Cuatro Tentadores; esta banda de asesinos, quienes recapitula el pasado mundano y político del canciller-arzobispo, propone una versión banal de su muerte. Mientras tanto, los espectadores vivencian la profundidad del conflicto a través de las intervenciones del Coro.

Por otro lado, es conveniente recordar que esta obra teatral, con aire de grandeza antiqua y escenas de ritmo lento y parsimonioso, se escribió en la época del crecimiento del fascismo en Europa central y puede interpretarse como una advertencia para que los pobladores de los países afectados se opusieran a la tergiversación de los ideales de la Iglesia cristiana por parte del régimen nazi y los movimientos autoritarios y belicistas que lo secundaron en el continente europeo y fuera de él. 


\section{Dibliografía}

》Eliot T. S. (2015). Poetry and Drama. USA: Scholar's Choice Edition.

»Eliot T. S. (2016). Murder in the Cathedral. USA: Harcourt Brace \& Co.

» González Padilla. M. E. (1991) Poesía y teatro de T.S. Eliot. México: Universidad Nacional Autónoma de México.

» Tydeman, W. (2008). Text E Performance: Murder in the Cathedral and The Cocktail Part. Londres: Macmillan Education Ltd. 